\title{
Patients see proposed FDA opioid rules as painfully restrictive
}

When treating patients suffering from severe pain, doctors are often reluctant to recommend opioids, the most potent analgesics, because of federal scrutiny of prescribing practices and fear of addiction. Now, a new trifecta of initiatives by the US Food and Drug Administration (FDA) could make patients' access to oral opiates, such as morphine, fentanyl and oxycodone, and effective pain relief even more difficult. Although some people support the proposed tighter regulations and see them as safeguards against prescription drug abuse, individuals with unremitting pain and their caregivers have objected to the new policies.

In June, the agency ordered a number of drug makers to stop producing older opioids that had reached market before the approval process was put in place. And, last month, an FDA advisory panel recommended that two combination opioid-acetaminophin drugs be pulled from the market, owing to the liver toxicity of acetaminophen.

The most far-reaching initiative is a new mandatory requirement that companies producing opioids have an FDA-approved Risk Evaluation and Mitigation Strategy, or REMS, before the agency will approve a drug or allow it to stay on the market. Until now, risk management programs have been voluntary and inadequate in keeping these drugs out of the hands of abusers, according to information presented by the FDA.

Abuse, overdoses and deaths from prescription opioids have edged up in the US from $4.7 \%$ of the population in 2002 to $5 \%$ in 2007 , despite voluntary programs, and are especially on the rise among young people, according to estimates by the National Institute on Drug Abuse (NIDA), the FDA, and the Substance Abuse and Mental Health Administration, according to NIDA's Wilson Compton.

"The FDA believes that establishing a REMS for opioids will reduce these risks while still ensuring that patients with legitimate need for these drugs will continue to have appropriate access," the FDA stated in a press release in February of this year. In September 2007, Congress gave the agency new authority to require REMSs and the power to revoke or prevent drug approval without them. In July, Onsolis became the first new opioid with a REMS to be approved after the new rules were put in place.

However, in late May, the American Pain Society issued a statement saying that the attempt to regulate only long-acting drugs

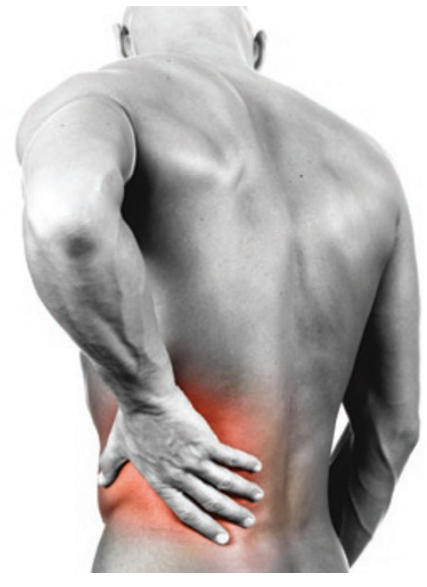

New requirements

The FDA is considering establishing patient and physician registries for opioids, as well as special training and certification for physicians and pharmacists, and is stipulating that the drugs be dispensed only in certain healthcare settings.

Parents of opioid addicts have for years urged the FDA to take OxyContin (Purdue Pharma), an extended-release version of oxycodone, off the market. Speaking at the May FDA meeting, Joanne Peterson, founder of the Massachusettsbased family support group Learn to Cope, urged the agency to ban the medication, which is used to treat pain associated with severe injuries, fractures and cancer.

Pain experts and pharmacists have suggested Hurting for change: More drug options sought

"will drive prescribers, users and especially misusers to other less stringently regulated opioids."

"REMS pits the interests of two communities against each other-cancer patients and drug abusers — and potentially stigmatizes millions patients without necessarily reducing risk diversion of drugs and abuse," says Kathleen Foley, attending neurologist in the pain and palliative care service of Memorial SloanKettering Cancer Center in New York. In particular, registries for physicians, patients or pharmacists would be a deterrent to patients' ability to access opioids, she adds. ways to prevent potential drug abuse without creating hardship for prescribers and their patients. These suggested measures include limiting the number of pills dispensed per pharmacy visit and launching a federal 'buy-back' program to dispose of unused medication.

The period for public commenting on the FDA's proposed opioid regulations ended on 30 June, and the agency has not yet indicated when it will publish its final REMS requirements."The agency will work diligently, but needs time in establishing a best path forward," says Crystal Rice, a spokesperson for the FDA's Center for Drug Evaluation and Research.

Vicki Brower, New York

\section{NIH stem cell rules expand funding}

Four months after an executive order from US President Barack Obama, stem cell funding guidelines issued by the US National Institutes of Health (NIH) trulyended the 2001 restriction limiting federal funding to research involving just 21 usable human embryonic stem cell lines.

The rules, which went into effect on 7 July, call for a registry of fundable lines. Human embryonic stem cell lines created going forward will be allowed if they are derived from unused embryos created through in vitro fertilization and given by donors who have undergone a thorough informed consent process.

Many of the nearly 700 lines that have already been created with private funding will be reviewed by an advisory committee. If they meet guidelines held by institutions such as the International
Society for Stem Cell Research, the lines will be grandfathered in and allowed, even if they don't fulfill all of the current NIH regulations.

The guidelines also open funding to disease-specific lines, but they do not permit lines that were created by somatic cell nuclear transfer or parthenogenesistechniques that could be used for cloning human cells.

"Now, we have to hope for two things," says Geoff Lomax, a lead member of the Interstate Alliance on Stem Cell Research. "The first is that this review process works in an expedient way. The second is that, down the road, we can incorporate intelligent guidelines for techniques that, while scary if misunderstood, are important avenues of research."

Stu Hutson, Gainesville, Florida 